\title{
Using data from schizophrenia outcome study to estimate the time to treatment outcome and the early-response cut-off score that predicts outcome at week 16
}

\author{
Justus UChenNA ONU1 \\ https://orcid.org/0000-0002-4567-7096 \\ JUDE UZOMA OHAER ${ }^{2}$ \\ https://orcid.org/0000-0002-2370-7100 \\ Department of Mental Health, Faculty of Medicine, Nnamdi Azikiwe University, Nnewi Campus, Awka, Nigeria. \\ 2 Department of Psychological Medicine, University of Nigeria, Nsukka, Enugu Campus, Enugu State, Nigeria.
}

Received: 04/24/2019 - Accepted: 11/05/2019

DOI: 10.1590/0101-60830000000234

\begin{abstract}
Background: Being able to make an estimation of the time to clinical outcome, and making predictions early during treatment about the possibility of later response/non-response to treatment, is an important asset that can help to guide treatment strategies and counsel patients and caregivers about treatment expectations. Objectives: The study aimed to determine the time course to treatment outcome and the psychopathological cut-off score at week 4 that predicts outcome at week 16. Methods: This was a naturalistic follow-up study of 160 incident cases of schizophrenia over 16 weeks. Four intervals of follow-up clinical assessments were done. Standard criteria for response and remission were applied. Results: The mean (median) times, in weeks, to response and remission using Brief Psychiatric Rating Scale (BPRS) data were 8.1(8.0); 8.4(8.0); and 10.9 (12.0), respectively. The Areas Under the Curves were high, for response (0.909; 95\% C.I., 0.85-0.97) and remission (0.86; 95\% C.I., 0.81 -0.94) at week 16 . A cut-off score of $20.7 \%$ reduction in the total BPRS score at week 4 , predicted response status (79.5\% sensitivity, $84.2 \%$ specificity) and remission status ( $77.6 \%$ sensitivity, $73.3 \%$ specificity) at week 16 . In addition, a cut-off of $10.21 \%$ reduction in the total Scale for Assessment of Negative Symptoms (SANS) score at week 4, predicted response (70.8\% sensitivity, $95.5 \%$ specificity) at week 16. Discussion: The results are in line with the general clinical impression that, by 2 months, most acutely ill inpatients are fit for discharge; and introduced for further investigation $10.21 \%$ reduction in SANS Score as a marker of treatment resistance in schizophrenia.
\end{abstract}

Onu JU et al. / Arch Clin Psychiatry. 2020;47(3):65-70

Keywords: Time-to-outcome, early-response, cut-off, prediction, schizophrenia.

\section{Introduction}

Schizophrenia is a disorder with varied pathophysiology and heterogeneous treatment outcome across cultures ${ }^{1}$. Being able to make an informed estimation about the time to clinical outcome events (i.e., response, remission and recovery), and making predictions early during treatment about the possibility of later response/ non-response to treatment among patients with schizophrenia, is an important asset that can help to guide treatment strategies and counsel patients and caregivers about treatment expectations ${ }^{2}$. The best guide for such estimates is one derived from follow-up studies of first- episode patients.

Many factors are considered when making decisions on the optimum duration of therapeutic trial either in clinical or research situations among schizophrenia patients. An important consideration is balancing the negative consequences of prematurely terminating a therapeutic trial, with the negative consequences of prolonging an ineffective treatment ${ }^{3}$. In Africa, there is dearth of data that suggest how long a therapeutic trial should last, or what volume or percentage of symptom reduction early in treatment predicts response/nonresponse later on in treatment. Emsley et al. ${ }^{4}$ and Lieberman et $a l .5$ found that the median time to response and remission among schizophrenia patients on treatment was 3 and 11 weeks, respectively. Correll et al. ${ }^{2}$ found that failure to achieve $20 \%$ improvement in symptoms after 1 week predicted non-response after 4 weeks. In addition, Kane et al.6,7 in their widely accepted definition of drugrefractoriness pegged treatment non-response as failure to achieve at least $20 \%$ reduction in the total Brief Psychiatry Rating Scale (BPRS) score by 6 weeks of optimal treatment. However, Gallego et al. ${ }^{8}$ using receiver operating characteristics analyses did not find any level of percent symptom reduction that was clinically useful as a predictor of response by week 16 .
The validity of these observations has not been tested in African populations, where the clinical manifestations and treatment outcome have been postulated to be different from Caucasian populations ${ }^{9-11}$. Using standard operational definitions ${ }^{6,12,13}$, this study aimed to estimate the mean and median times to treatment response, remission and recovery, as well as the early response cut-off in percentage reduction of symptoms that would predict response/ remission/recovery at 16 weeks of naturalistic follow-up of a cohort of Nigerian patients with first-episode schizophrenia.

\section{Subjects and methods}

Details about the recruitment of patients, operational definitions, assessment for family history of illness, follow-up and clinical outcome (response/ remission/ social recovery) are being presented elsewhere (Onu \& Ohaeri, In Press). This was a naturalistic longitudinal followup outcome study which took place at the Federal Neuropsychiatric Hospital (FNH), Enugu, Nigeria. Participants were recruited from April to July 2016. Consecutive incident cases of schizophrenia, who presented at the hospital, aged 18-49 years, and resident within Enugu metropolis (to facilitate follow-up) were invited, with their available family members, to participate in the study. Patients with schizophrenia of suspected organic aetiology, including substance use disorders, medical or psychiatric co-morbidities, or both, were excluded. Diagnosis of schizophrenia was confirmed using Mini International Neuropsychiatric Interview (MINI) ${ }^{14}$. Patients were assessed at baseline and followed up at intervals of 4 weeks for 16 weeks. Symptom changes and functional status were assessed at baseline and at each interval of treatment follow-up, using the Brief Psychiatry Rating Scale (BPRS) ${ }^{15}$, Scale for Assessment of Negative Symptoms (SANS) ${ }^{16}$, as well as Global Assessment of Functioning (GAF) ${ }^{17}$, and the World Health Organization Disability Assessment Scale (WHODAS) ${ }^{18}$, respectively. 
Treatment response, remission and recovery: Response was defined as symptom reduction greater than $50 \%$ of the baseline scores in BPRS and SANS scores during each period of follow-up ${ }^{13}$. Symptomatic remission was defined as a rating of 'mild' or less, concurrently on the following seven BPRS items (BPRS only criteria): grandiosity, suspiciousness, unusual thought content, hallucinatory behavior, conceptual disorganization, mannerism/posturing, and blunted affect ${ }^{13}$. In addition, as suggested by Andreasen ${ }^{13}$ when using SANS, a score of 2 or less on the following 4 SANS items: affective flattening, avolition-apathy, anhedonia-asociality, and alogia (SANS criteria). Functional or social recovery (also termed functional remission) was based on both clinical and psychosocial functional dimensions as proposed by Jaaskelainen et al. ${ }^{12}$. Hence, social recovery in this study was defined as: (a) maintaining symptomatic remission as described above through the particular follow-up period; and (b) having a GAF score greater than or equal to 61 . This GAF score indicates that the subject is judged to be capable of returning to the premorbid level of psychosocial functioning ${ }^{17}$.

Mode of onset of illness was dichotomized as: acute vs. chronic (insidious). Acute onset means that the positive symptoms of schizophrenia dramatically rose to a crescendo within one month, with a sudden deterioration from the premorbid level of functioning in that period. Insidious onset means that there was a gradual deterioration in premorbid level of functioning that spread over several months, along with the appearance of negative symptoms, while the onset of positive symptoms was slow and occurred after a period of noticeable change in premorbid functioning ${ }^{19}$.

Family history of mental illness was assessed with the Family Interview for Genetic Studies ${ }^{20}$. The FIGS was developed by principal investigators in the National Institute of Mental Health (NIMH) Schizophrenia and Bipolar Disorder Genetics Initiatives and NIMH extramural program staff in 1992, as a guide for systematically collecting information about relatives in family genetic studies of these disorders.

\section{Ethical considerations}

Ethical approval was obtained from the Ethical Committee of the Federal Neuropsychiatric Hospital Enugu, Enugu State, Nigeria. International ethical norms and standards were strictly adhered to. After explaining the objectives and procedures, consenting patients were required to sign the written informed consent, with the understanding that they could withdraw from the study at any stage without any adverse impact on their right to treatment.

\section{Data analysis}

Mean and median times to response, remission and recovery were estimated using Kaplan-Meier survival analysis, which also estimated significant differences in time to event for variables, such as: gender, family history of illness, mode of onset of illness, and adequacy of social support in the cohort. Significant differences in time to outcome event between categories of subjects (e.g., male/ female, satisfactory/non-satisfactory social support, family history of illness, and age at onset of illness) were assessed by the log rank (Mantel-Cox), Breslow (generalized Wilcoxon) and Tarone-Ware. However, we present the Breslow results because they were similar to the others. For the ROC analyses (i.e., the early percentage reduction in total BPRS cut-off score that would predict outcome at week 16), we used the response at week 4 , versus, the outcome at week 16 . This was because the first follow-up assessment was at week 4, in line with the recommendation of Trivedi et al. ${ }^{21}$.

\section{Results}

The socio-demographic and some clinical characteristics of the 160 participants shows that they were mostly young (mean age 31.13 \pm 12.50 ), and the mean age at onset of schizophrenia and duration of illness were $26.33 \pm 12.15$ years and $63.18 \pm 74.15$ months, respectively. Majority (51.2\%) were females, never married (66.3\%), with at least high school education (74.4\%), and unemployed (63.8\%). The attrition rate at week 16 was $29.4 \%$; hence 113 subjects (out of 160) were available for assessment of response, remission and recovery at that time. Table 1 shows that, for the BPRS data, the mean (median) times, in weeks, to response, remission and recovery, were, respectively: 8.1 (8.0); $8.4(8.0)$; and 10.9 (12.0). The equivalent results using SANS criteria were as follows: 9.1 (8.0); 9.4 (8.0); and 11.1 (12.0), respectively. The tendency for longer mean time to response, remission and recovery for SANS, vs. BPRS, did not reach significance (Standardized Effect Size for response: 0.19, 95\% CI: 0.06-0.44). There were no significant differences in gender (Tables 2-4; Figure 1), marital status and employment status (Tables 2-4) in times to response, remission and social recovery. However, there was a tendency for those who were married and employed to have shorter time to these outcome events (For the BPRS data only, employment status was associated with earlier time to recovery $-\mathrm{P}<0.05$ : Table 4 ). These indices of social advantage were manifest as significantly shorter time to response $(\mathrm{p}<0.001)$ (Table 2$)$ and recovery $(\mathrm{p}<0.04)$ (Table 4) for subjects with perception of satisfactory social support.

Subjects with acute onset of illness had significantly shorter time to response $(\mathrm{p}<0.05)$ (Table 2$)$ and remission $(\mathrm{p}<0.005)$ (Table 3$)$, than those with insidious onset. The tendency for those with no family history of mental illness to have shorter time to response and remission, did not reach significance $(\mathrm{p}>0.05)$.

For the ROC analyses (Figures 1a and 1b), using BPRS data for response at week 4 to predict outcome at week 16, the Areas Under the Curves (AUC) met the recommended cut-off for significance, for response $(0.901,95 \%$ CI: $0.85-0.963)$, remission $(0.875$; 95\% CI: $0.811-0.938)$ and recovery (0.874; 95\% CI: 0.84-0.944) at week 16 . In addition, the cut-off score of $20.7 \%$ reduction in BPRS score at week 4 , predicted response (79.5\% sensitivity, $84.2 \%$ specificity), remission (77.6\% sensitivity, $73.3 \%$ specificity) and recovery ( $88 \%$ sensitivity, $67.7 \%$ specificity) at week 16 . The equivalent AUC values (95\% CI) for the SANS data were: 0.897 (0.84-0.935), 0.84 (0.775-0.919), 0.874 and (0.804-0.944), respectively, for response, remission and recovery. Also, a cut-off of $10.21 \%$ reduction in SANS total score at week 4 , predicted response $(70.8 \%$ sensitivity, $95.5 \%$ specificity), remission (70.8\% sensitivity, $91.9 \%$ specificity) and recovery (78.0\% sensitivity, $82.7 \%$ specificity) at week 16 .

\section{Discussion}

The highlights of the findings of this 16-week naturalistic follow-up study of a Nigerian schizophrenia cohort are: (1) the mean (median)

Table 1. The mean and median time to response, remission and recovery among schizophrenia patients: survival analyses

\begin{tabular}{|c|c|c|c|c|}
\hline \multirow{2}{*}{ Outcome } & \multicolumn{2}{|c|}{ Using BPRS Criteria } & \multicolumn{2}{c|}{ Using SANS Criteria } \\
\cline { 2 - 5 } & Mean in weeks (95\% CI) & Median in weeks (95\% CI) & Mean in weeks (95\% CI) & Median in weeks (95\% CI) \\
\hline Response & $8.1(7.2-9.0)$ & $8.0(6.7-9.3)$ & $9.1(8.2-10.1)$ & $8.0(6.5-9.5)$ \\
\hline Remission & $8.4(7.5-9.2)$ & $8.0(7.0-9.0)$ & $9.4(9.0-9.5)$ & $8.0(6.9-9.5)$ \\
\hline Recovery & $10.9(9.9-11.7)$ & $12.0(10.6-13.4)$ & $11.1(10.3-11.7)$ & $12.0(10.5-13.3)$ \\
\hline
\end{tabular}

NB: Response is defined as $\geq 50 \%$ reduction in total BPRS \& SANS scores, Remission using BPRS = Scores $\leq 2$ in psychosis BPRS items (grandiosity, suspiciousness, unusual thought content, hallucinatory behaviour, conceptual disorganization, mannerism/posturing, and blunted affect). Using SANS, a score of 2 or less on the following 4 SANS items: affective flattening, avolition-apathy, anhedonia-asociality, and alogia. Recovery = maintenance of remission + GAF-score $\geq 61$. 
times, in weeks, to response, remission and social recovery were 8.1(8.0); 8.4(8.0); and 10.9 (12.0), respectively, for the BPRS data, $v s$. 9.1(8.0), 9.4 (8.0) and 11,1 (12.0), for the SANS data; (2) the time to response, remission and recovery differed with regards to baseline variables such as social support and mode of onset of illness; (3) the tendency for longer mean time to response, remission and recovery for negative symptoms, did not reach significance (Standardized Effect Size for response: 0.19, 95\% CI: 0.06-0.44); (4) early response at week 4 significantly predicted 16-week response, remission and recovery; and (5) a threshold for early response of $\geq 20.7 \%$ BPRSscore reduction and $\geq 10.21 \%$ for the SANS at week 4 had significant predictive validity for later response, remission and recovery

For the survival analyses, our choice of 4 weeks as the first outcome assessment is in line with the American Psychiatric Association's practice guideline recommendation that an initial trial of 4-6 weeks generally is needed to determine if the patient will have any symptomatic response, although symptoms can continue to improve over longer periods of time ${ }^{22,23}$. Understandably, our mean/median time to response, based on $>50 \%$ reduction in psychopathology, is higher than the results for studies where response was defined as $>20 \%$ reduction, and median time to response was 3 weeks $^{2}$. Furthermore, although our patients were incident cases, the mean duration of untreated psychosis was long (about 5 years), a factor that has been consistently associated with poor treatment response $\mathrm{e}^{24,25}$. Perkins et al. found that shorter duration of untreated psychosis was associated with greater response to antipsychotic treatment, as measured by severity of global psychopathology, positive symptoms, negative symptoms and functional outcome ${ }^{26}$. However, our findings on time to response and remission support a recent recommendation by Kane et al. on guidelines for defining

Table 2. Time to Response: by baseline independent variables among schizophrenia patients

\begin{tabular}{|c|c|c|c|c|c|c|}
\hline \multirow[t]{2}{*}{ Variables } & \multicolumn{3}{|c|}{ Time to Response Using BPRS Criteria } & \multicolumn{3}{|c|}{ Time to Response Using SANS Criteria } \\
\hline & Mean (SE) & Median (SE) & Stat. (p-value) & Mean (SE) & Median (SE) & Stat. (p-value) \\
\hline $\begin{array}{l}\text { Gender } \\
\text { Male } \\
\text { Female }\end{array}$ & $\begin{array}{l}8.4(0.7) \\
7.8(0.5)\end{array}$ & $\begin{array}{l}8.0(0.0) \\
8.0(0.7)\end{array}$ & $0.59(0.44)$ & $\begin{array}{l}9.5(0.7) \\
8.7(0.6)\end{array}$ & $\begin{array}{l}8.0(1.7) \\
8.0(0.7)\end{array}$ & $0.0(1.99)$ \\
\hline $\begin{array}{l}\text { Marital Status } \\
\text { Single } \\
\text { Married }\end{array}$ & $\begin{array}{l}8.2(0.6) \\
8.1(0.8) \\
\end{array}$ & $\begin{array}{c}8(0.8) \\
8.0(1.2)\end{array}$ & $0.12(0.73)$ & $\begin{array}{l}9.5(0.6) \\
8.0(0.9)\end{array}$ & $\begin{array}{l}8.0(1.0) \\
8.0(1.1)\end{array}$ & $2.0(0.15)$ \\
\hline $\begin{array}{l}\text { Employment Status } \\
\text { Unemployed } \\
\text { Employed }\end{array}$ & $\begin{array}{l}8.7(0.6) \\
6.9(0.5) \\
\end{array}$ & $\begin{array}{l}8.0(0.8) \\
4.0(0.0)\end{array}$ & $2.70(0.11)$ & $\begin{array}{l}9.7(0.6) \\
8.3(0.7)\end{array}$ & $\begin{array}{l}8.0(1.0) \\
8.0(1.2)\end{array}$ & $1.6(0.21)$ \\
\hline $\begin{array}{l}\text { Social Support } \\
\text { Satisfactory } \\
\text { Unsatisfactory }\end{array}$ & $\begin{array}{l}4.9(0.3) \\
7.5(0.5)\end{array}$ & $\begin{array}{l}4.0(0.0) \\
4.0(0.0)\end{array}$ & $6.60(0.01)$ & $\begin{array}{l}6.2(0.6) \\
8.7(0.6)\end{array}$ & $\begin{array}{l}4.0(0.0) \\
8.0(1.1)\end{array}$ & $4.0(0.04)$ \\
\hline $\begin{array}{l}\text { Mode of Onset } \\
\text { Insidious } \\
\text { Acute }\end{array}$ & $\begin{array}{l}8.9(0.7) \\
7.3(0.6)\end{array}$ & $\begin{array}{l}8.0(0.9) \\
4.0(0.0) \\
\end{array}$ & $3.90(0.05)$ & $\begin{array}{c}8.0(0.7) \\
10.3(0.7)\end{array}$ & $\begin{array}{l}8.0(0.0) \\
8.0(1.2)\end{array}$ & $7.8(0.005)$ \\
\hline $\begin{array}{l}\text { Family History } \\
\text { Positive } \\
\text { Negative }\end{array}$ & $\begin{array}{l}8.4(0.6) \\
7.1(0.6)\end{array}$ & $\begin{array}{l}8.0(0.7) \\
4.0(0.0)\end{array}$ & $1.70(0.19)$ & $\begin{array}{l}9.0(0.6) \\
9.4(0.8)\end{array}$ & $\begin{array}{l}8.0(0.8) \\
8.0(1.6)\end{array}$ & $0.07(0.79)$ \\
\hline
\end{tabular}

NB: response is defined as $250 \%$ reduction in total BPRS and SANS score; SE: standard error.

Statistical significance was based on Breslow (generalized Wilcoxon).

Table 3. Time to Remission: by baseline independent variables among schizophrenia patients

\begin{tabular}{|c|c|c|c|c|c|c|}
\hline \multirow[t]{2}{*}{ Variables } & \multicolumn{3}{|c|}{ Time to Remission Using BPRS Criteria } & \multicolumn{3}{|c|}{ Time to Remission Using SANS Criteria } \\
\hline & Mean (SE) & Median (SE) & Stat. (p-value) & Mean (SE) & Median (SE) & Stat. (p-value) \\
\hline $\begin{array}{l}\text { Gender } \\
\text { Male } \\
\text { Female }\end{array}$ & $\begin{array}{l}8.2(0.7) \\
8.6(0.6)\end{array}$ & $\begin{array}{l}8.0(0.8) \\
8.0(0.6)\end{array}$ & $1.14(0.29)$ & $\begin{array}{l}7.9(0.5) \\
8.6(0.6)\end{array}$ & $\begin{array}{l}8.0(1.0) \\
8.0(0.7)\end{array}$ & $0.3(0.62)$ \\
\hline $\begin{array}{l}\text { Marital Status } \\
\text { Single } \\
\text { Married }\end{array}$ & $\begin{array}{l}8.6(0.5) \\
7.9(0.8)\end{array}$ & $\begin{array}{l}8.0(0.5) \\
8.0(0.0) \\
\end{array}$ & $0.22(0.64)$ & $\begin{array}{l}8.9(0.5) \\
7.2(0.7) \\
\end{array}$ & $\begin{array}{l}8.0(0.8) \\
8.0(0.6)\end{array}$ & $3.2(0.08)$ \\
\hline $\begin{array}{l}\text { Employment Status } \\
\text { Unemployed } \\
\text { Employed }\end{array}$ & $\begin{array}{l}8.7(0.6) \\
7.9(0.6)\end{array}$ & $\begin{array}{l}8.0(0.7) \\
8.0(0.7)\end{array}$ & $0.27(0.60)$ & $\begin{array}{l}8.8(0.6) \\
8.0(0.6)\end{array}$ & $\begin{array}{l}8.0(0.8) \\
8.0(0.8)\end{array}$ & $0.8(0.39)$ \\
\hline $\begin{array}{l}\text { Social Support } \\
\text { Satisfactory } \\
\text { Unsatisfactory }\end{array}$ & $\begin{array}{l}6.1(0.5) \\
7.9(0.6)\end{array}$ & $\begin{array}{l}4.0(0.0) \\
8.0(0.7)\end{array}$ & $2.63(0.11)$ & $\begin{array}{l}5.6(0.4) \\
8.0(0.6)\end{array}$ & $\begin{array}{l}4.0(0.0) \\
8.0(0.7)\end{array}$ & $6.7(0.01)$ \\
\hline $\begin{array}{l}\text { Mode of Onset } \\
\text { Insidious } \\
\text { Acute }\end{array}$ & $\begin{array}{l}9.5(0.7) \\
7.4(0.6)\end{array}$ & $\begin{array}{l}8.0(0.6) \\
8.0(0.0)\end{array}$ & $8.10(0.005)$ & $\begin{array}{l}7.2(0.6) \\
9.7(0.6)\end{array}$ & $\begin{array}{l}8.0(0.0) \\
8.0(0.7)\end{array}$ & $13.6(<0.001)$ \\
\hline $\begin{array}{l}\text { Family History } \\
\text { Positive } \\
\text { Negative }\end{array}$ & $\begin{array}{l}8.7(0.5) \\
7.9(0.7) \\
\end{array}$ & $\begin{array}{l}8.0(0.6) \\
8.0(0.9)\end{array}$ & $2.60(0.11)$ & $\begin{array}{l}8.1(0.5) \\
8.8(0.7)\end{array}$ & $\begin{array}{l}8.0(0.7) \\
8.0(0.9)\end{array}$ & $0.2(0.65)$ \\
\hline
\end{tabular}

NB: remission using BPRS = Scores $\leq 2$ in the following BPRS items (Grandiosity, Suspiciousness, unusual thought content, Hallucinatory behavior, conceptual disorganization, mannerism/posturing, and blunted affect). Remission in SANS = Scores $\leq 2$ in the following SANS items (Affective flattening, Avolition-apathy, Anhedonia-asociality, and Alogia). SE: standard error. Statistical significance was based on Breslow (generalized Wilcoxon). 
treatment resistance among schizophrenia patients that suggest a treatment duration of $\geq 6$ weeks and $\leq 12$ weeks to re-evaluate for non-response to treatment ${ }^{7}$. This is in line with recent evidence indicating that with prolonged treatment, most patients with acute schizophrenia would respond to treatment ${ }^{8}$. Consistent with the literature, the negative symptoms in SANS tended to confer longer time to treatment outcome, although the effect size was not significant; and the early achievement of response in SANS score was associated with good clinical outcome at week 16 $6^{27-30}$.
Our findings on social support and acute onset of illness are consistent with other studies that have found that adequate social support and acute onset are promotive of early response to treatment ${ }^{31,32}$. Other factors reported in the literature include: employment, a shorter duration of illness, female sex, being married, younger age, tertiary education, and shorter duration of untreated psychosis ${ }^{24}$. Our results did not support the later findings, although there were trends in that direction for being married and being employed, factors which could be viewed as contributing to social

Table 4. Time to Social Recovery: by baseline independent variables among schizophrenia patients

\begin{tabular}{|c|c|c|c|c|c|c|}
\hline \multirow[t]{2}{*}{ Variables } & \multicolumn{3}{|c|}{ Time to Recovery Using BPRS Criteria } & \multicolumn{3}{|c|}{ Time to Recovery Using SANS Criteria } \\
\hline & Mean (S.E) & Median (SE) & Stat. (p-value) & Mean (SE) & Median (SE) & Stat. (p-value) \\
\hline $\begin{array}{l}\text { Gender } \\
\text { Male } \\
\text { Female } \\
\end{array}$ & $\begin{array}{l}11.4(0.6) \\
10.4(0.7) \\
\end{array}$ & $\begin{array}{c}12.0(1.0) \\
8.0(0.7) \\
\end{array}$ & $1.60(0.21)$ & $\begin{array}{l}11.0(0.4) \\
10.6(0.7) \\
\end{array}$ & $\begin{array}{c}12.0(0.9) \\
8.0(0.7)\end{array}$ & $1.5(0.20)$ \\
\hline $\begin{array}{l}\text { Marital Status } \\
\text { Single } \\
\text { Married }\end{array}$ & $\begin{array}{l}11.2(0.5) \\
10.0(0.8) \\
\end{array}$ & $\begin{array}{c}12.0(0.0) \\
8.0(0.7) \\
\end{array}$ & $2.10(0.15)$ & $\begin{array}{l}11.6(0.6) \\
10.3(0.7) \\
\end{array}$ & $\begin{array}{c}12.0(0.1) \\
8.0(0.7) \\
\end{array}$ & $2.0(0.14)$ \\
\hline $\begin{array}{l}\text { Employment Status } \\
\text { Unemployed } \\
\text { Employed }\end{array}$ & $\begin{array}{c}11.7(0.6) \\
9.7(0.6)\end{array}$ & $\begin{array}{l}12(1.0) \\
8.0(0.6)\end{array}$ & $3.82(0.05)$ & $\begin{array}{c}11.8(0.6) \\
9.6(0.5)\end{array}$ & $\begin{array}{l}12(1.0) \\
8.0(0.6)\end{array}$ & $3.7(0.06)$ \\
\hline $\begin{array}{l}\text { Social Support } \\
\text { Satisfactory } \\
\text { Unsatisfactory }\end{array}$ & $\begin{array}{c}8.7(0.6) \\
11.2(0.6)\end{array}$ & $\begin{array}{c}8.0(0.7) \\
12.0(1.2)\end{array}$ & $4.12(0.04)$ & $\begin{array}{c}8.0(0.3) \\
11.0(0.6)\end{array}$ & $\begin{array}{c}8.0(0.5) \\
12.0(1.2)\end{array}$ & $4.9(0.03)$ \\
\hline $\begin{array}{l}\text { Mode of Onset } \\
\text { Insidious } \\
\text { Acute }\end{array}$ & $\begin{array}{l}11.6(0.7) \\
10.3(0.6)\end{array}$ & $\begin{array}{c}12.0(1.1) \\
8.0(0.7)\end{array}$ & $2.80(0.09)$ & $\begin{array}{l}11.8(0.7) \\
10.7(0.6)\end{array}$ & $\begin{array}{c}12.0(1.1) \\
8.0(0.7)\end{array}$ & $2.9(0.08)$ \\
\hline $\begin{array}{l}\text { Family History } \\
\text { Positive } \\
\text { Negative }\end{array}$ & $\begin{array}{l}10.4(0.6) \\
11.5(0.7)\end{array}$ & $\begin{array}{c}12(0.8) \\
12.0(1.3)\end{array}$ & $1.41(0.24)$ & $\begin{array}{l}10.5(0.6) \\
11.5(0.7)\end{array}$ & $\begin{array}{c}12(0.8) \\
12.0(1.3)\end{array}$ & $1.5(0.26)$ \\
\hline
\end{tabular}

NB: recovery = maintenance of remission + GAF-score $\geq 61$, SE: standard error. Statistical significance was based on Breslow (generalized Wilcoxon).

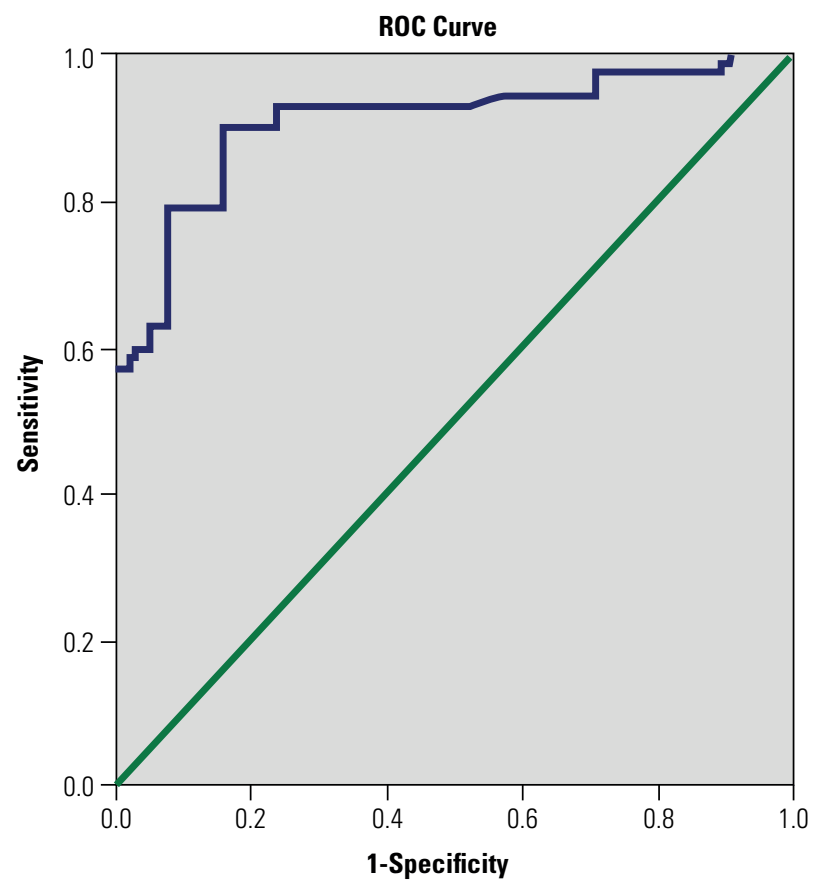

Diagonal segments are produced by ties.

Figure 1a. Receiver Operating Characteristics curve showing plot of \% reduction in total BPRS score at week 4 vs. response status (responded/not responded) at week 16. Note: Area under the curve (AUC) (95\% C.I.): 0.909 (0.85-0.963). With 20.72\% BPRS reduction at week 4, prediction of response status at week 16 had $79.5 \%$ sensitivity, $84.2 \%$ specificity.

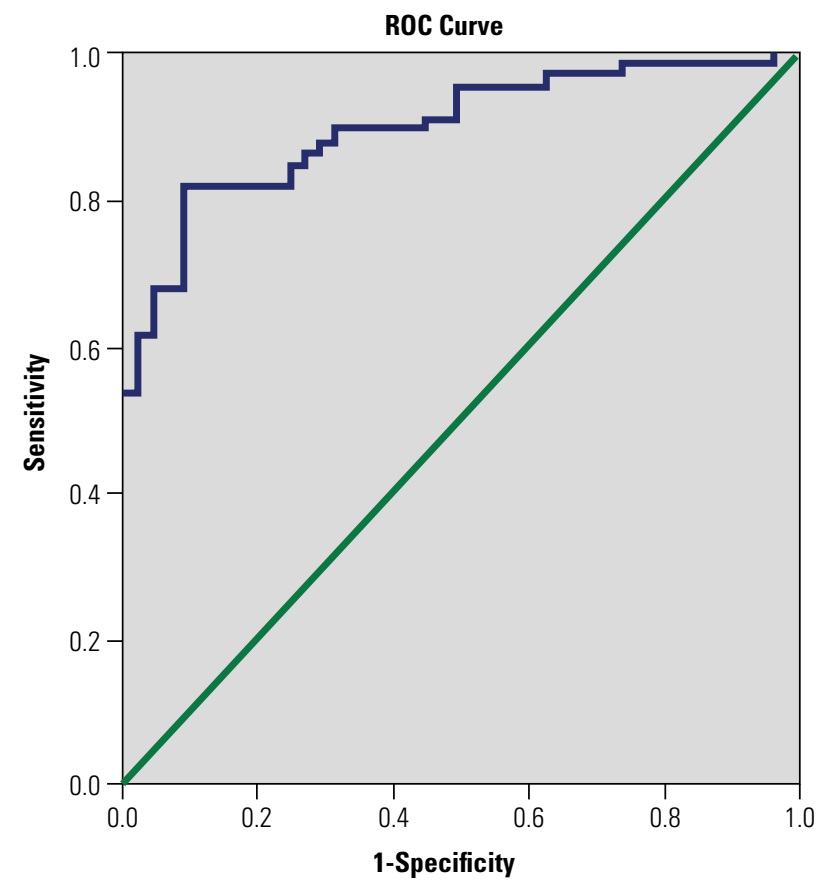

Figure 1b. Receiver Operating Characteristics curve showing plot of $\%$ reduction in total SANS score at week 4 vs. response status (responded/not responded) at week 16. Note: Area under the curve (AUC) (95\% C.I.): 0.897 (0.84-0.955). With $10.21 \%$ SANS reduction at week 4, prediction of response status at week 16 had $70.8 \%$ sensitivity, $95.5 \%$ specificity. 
support. The long held impression is that the traditional social support in the African extended family system constitutes a huge social capital for patients with schizophrenia, and could positively modify the clinical course of the disease ${ }^{33,34}$.

For the ROC analyses, we found that early response to treatment at week 4 predicted good response at week 16. This is consistent with Agid et al. 35 early-onset of response hypothesis of antipsychotic drug action, which suggests that early response to medication is a stable predictor of subsequent response. Studies have evaluated the predictive value of early response to treatment among schizophrenia patients ${ }^{36-38}$. The results largely agree that, early response is a significant predictor of later response $e^{4,5,38}$. However, variations exist on which week of treatment has the best predictive validity for response at later stages of treatment ${ }^{36}$. Studies have evaluated response at weeks 1, 2, 3, 4, and 8. Although there is much support for the predictive value of response at 2 weeks $s^{4,5,36}$, it has been suggested that the first critical decision point for assessing treatment outcome is 4 weeks ${ }^{23}$, and this has been incorporated in treatment guidelines ${ }^{22,23}$. In line with our findings, Gallegos et al. ${ }^{8}$ reported that early response at week 4 (not 2 or 8 ) was associated with responder status at week 16 . Taken together, our data support the impression that re-evaluation of treatment in schizophrenia patients for response should occur within the first 4 weeks of commencing treatment, to identify potential candidates for treatment resistance early on in the treatment trajectory. In addition, our finding of $\geq 20.7 \%$ BPRS-score reduction at week 4 as having significant predictive validity for outcome events is consistent with the literature ${ }^{38}$. This finding validates the recommendation of Kane et al. ${ }^{6}$, that treatment resistance be defined as $<20 \%$ reduction in BPRS total score after adequate psychopharmacological treatment. An important addition to the literature is the finding that $\geq 10.21 \%$ SANS-score reduction at week 4 was predictive of response, remission and recovery at week 16 .

Negative symptoms have been identified as important determinants of psychosocial functioning in schizophrenia ${ }^{27-29}$. In the prediction of global psychosocial functioning, negative symptom severity was the most important factor ${ }^{30}$.

\section{Limitations and strengths}

First, being a naturalistic study (as distinct from a drug trial), we could not control treatment decisions, such as dosage/type of medications, and whether to augment or change medication when there was inadequacy of response. However, this design is in line with the international follow-up studies in the literature, and makes our results comparable with those studies. Second, treatment adherence was judged only by the verbal testimony of patients and family caregivers. Although this is less rigorous than assaying blood levels of drugs, our experience is that the accompanying family caregivers could be trusted to determine treatment adherence, Third, the relatively high attrition rate meant that we could not account for the outcome in over a quarter of the original cohort. We note that attrition is a well-known problem in follow-up studies, and we tried to avoid this problem by including only patients living within the metropolis of our study area. The major strengths of the study are that: first, we have used rigorous statistical methods and stringent operational definitions of clinical outcome, for incident cases, who were predominantly neuroleptic naïve at baseline, to estimate the time to outcome events. Second, we have validated the psychopathological cut-off points that define treatment resistance in schizophrenia. In particular, in addition to the well- known $20 \%$ cut-off for the BPRS, we have indicated that $10.21 \%$ be considered for the SANS

\section{Conclusions}

The results are in line with the general clinical impression that, by 2 months, most acutely ill inpatients are fit for discharge in our practice setting; and support the popular use of $<20 \%$ reduction in BPRS psychopathological score, as a marker of treatment resistance in schizophrenia. We suggest that future studies could try to validate our finding of $<10.21 \%$ reduction in SANS score as a marker of treatment resistance. In the first such rigorously designed study from Africa, this cohort of Nigerians with first - episode schizophrenia, had similar treatment response patterns, in the short-term, with such patients in the international literature.

\section{Conflict of interest}

There is no conflict of interest.

\section{Contributors}

Justus Uchenna Onu was the principal investigator. However, the first and second authors contributed to the study design, analysis and interpretation of data, and drafting the manuscript. All the authors approved the final draft for submission.

\section{Role of funding sources}

Self-financed.

\section{Statement of ethics}

Ethical approval was obtained from the Ethical Committee of the Federal Neuropsychiatric Hospital Enugu, Enugu State, Nigeria. International ethical norms and standards were strictly adhered to. After explaining the objectives and procedures, consenting patients were required to sign the written informed consent, with the understanding that they could withdraw from the study at any stage without any adverse impact on their right to treatment.

\section{Acknowledgments}

The authors would like to thank Dr. Justus Uchenna Onwukwe, the immediate past Medical Director, Federal Neuropsychiatric Hospital, Enugu, for providing the enabling environment and some logistic support for this study. Additionally, we thank Mr. Louis Okachi of the Federal School of Statistics for his insightful comments on the statistical methods. We are grateful to the patients and their relatives, for freely giving of their time to participate in the study.

\section{References}

1. Haro JM, Novick D, Bertsch J, Karagianis J, Dossenback M, Jones PB. Cross-national clinical and functional remission rates: Worldwide Schizophrenia Out-patient Health Outcome (S-SOHO) Study. Br J Psychiatry. 2011;199(3):194-201.

2. Correll CU, Malhotra AK, Kaushik S, McMeniman M, Kane JM. Early prediction of antipsychotic response in Schizophrenia. Am J Psychiatry. 2003;160(11):2063-5.

3. Davis JM, Schaffer CB, Killian GA, Kinard C, Chan C. Important issues in the drug treatment of schizophrenia. Schizophr Bull. 1980;6(1):70-87.

4. Emsley R, Rabinowitz J, Medori R. Time course for antipsychotic treatment response in first-episode schizophrenia. Am J Psychiatry. 2006;163(4):743-5.

5. Lieberman JA, Jody D, Geisler S, Alvir J, Borenstein M, Loebel A, et al. Time course and biologic correlates of treatment response in first-episode schizophrenia. Arch Gen Psychiatry. 1993;50(5):369-76.

6. Kane J, Hognifeld G, Singer J, Meltzer H. Clozapine for the treatment-resistant schizophrenic. A double-blind comparison with chlorpromazine. Arch Gen Psychiatry. 1988;45(9):789-96.

7. Kane JM, Agid O, Baldwin ML, Howes O, Lindenmayer J, Marder S, et al. Clinical guidance on the identification and management of treatment-resistant schizophrenia. J Clin Psychiatry. 2019;80(2). pii: 18com12123.

8. Gallego JA, Robinson DG, Sevy SM, Napolitano B, McCormack J, Lesser ML, et al. Time to treatment response in first-episode schizophrenia: should acute treatment trials last several months? J Clin Psychiatry. 2011;72(12):1691-6.

9. Banerjee A. Cross-cultural variance of schizophrenia symptoms, diagnosis and treatment. Georgetown University Journal of Health Sciences. 2012;6(2):18-24. 
10. Viswanath B, Chaturvedi SK. Cultural aspects of major mental disorders: a critical review from an Indian perspective. Indian J Psychol Med. 2012;34(4):306-12.

11. Lim KM, Poland RE, Nakasaki G. Psychopharmacology and psychobiology of Ethnicity. Washington, DC: American Psychiatric Press; 1993. p. 59-61.

12. Jaaskelainen E, Juola P, Hirvonen N, McGrath JJ, Saha S, Isohanni M, et al. A systematic review and meta-analysis of recovery in schizophrenia. Schizophr Bull. 2013;39(6):1296-306.

13. Andreasen NC, Carpenter WT, Kane JM, Lasser RA, Marder SR, Weinberger DR. Remission in schizophrenia: proposed criteria and rationale for consensus. Am J Psychiatry. 2005;162(3):441-9.

14. Sheehan DV, Lecrubier Y, Harnett-Sheehan K, Amorim P, Janavs J, Weiller E, et al. The Mini-International Neuropsychiatric Interview (M.I.N.I.): the development and validation of a structured diagnostic psychiatric interview. J Clin Psychiatry. 1998;59 Suppl 20:22-33;quiz 34-57.

15. Overall JE, Gorham DR. The Brief Psychiatric Rating Scale. Psychol Rep. 1962;10:799-812.

16. Andreasen NC. The Scale for the Assessment of Negative Symptoms. Iowa: University of Iowa; 1983.

17. American Psychiatric Association. Diagnostic and Statistical Manual of Mental Disorders. 4th ed. Washington, DC: American Psychiatric Association; 1994.

18. World Health Organization. Measuring health and disability: Manual for WHO Disability Assessment Schedule (WHODAS 2.0). Geneva: World Health Organization; 2010

19. Ohaeri JU. Long-term outcome of treated schizophrenia in a Nigerian cohort. Retrospective analysis of 7-year follow-ups. J Nerv Ment Dis. 1993;181(8):514-6.

20. National Institute of Mental Health (NIMH). Genetics Initiative: Family Interview for Genetic Studies (FIGS). Rockville: National Institute of Mental Health; 1992.

21. Trivedi MH, Rush AJ, Wisniewski SR, Nierenberg AA, Warden D, Ritz $\mathrm{L}$, et al STAR ${ }^{\star} \mathrm{D}$ Study Team. Evaluation of outcomes with citalopram for depression using measurement-based care in STAR ${ }^{*} \mathrm{D}$ : implications for clinical practice. Am J Psychiatry. 2006;163(1):28-40.

22. Lehman AF, Lieberman JA, Dixon LB, McGlashan TH, Miller AL, Perkins DO, et al.; Steering Committee on Practice Guidelines. Practice guideline for the treatment of patients with schizophrenia, second edition. Am J Psychiatry. 2004;161(2 Suppl):1-56.

23. American Psychiatric Association. Guideline for the treatment of schizophrenia. 2nd ed. Washington, DC: American Psychiatric Association; 2010.

24. Black K, Peter L, Rui Q, Milliken H, Kopala LC. Duration of untreated psychosis predicts treatment outcome in an early psychosis program. Schizophr Res. 2001;47(2-3):215-22.

25. Verdox H, Liraud F, Bergey C, Assens F, Abalan F, van Os J. Is the association between duration of untreated psychosis and outcome confounded?
A two year follow-up study of first-admitted patients. Schizophr Res. 2001;49(3):231-41.

26. Perkins DO, Gu H, Boteva K, Lieberman JA. Relationship between duration of untreated psychosis and outcome in first-episode schizophrenia: a critical review and meta-analysis. Am J Psychiatry. 2005;162(10):1785804.

27. Kurtz MM. Symptoms versus neurocognitive skills as correlates of everyday functioning in severe mental illness. Expert Rev Neurother. 2006;6(1):47-56.

28. Ventura J, Hellemann GS, Thames AD, Koellner V, Nuechterlein KH. Symptoms as mediators of the relationship between neurocognition and functional outcome in schizophrenia: a meta-analysis. Schizophr Res. 2009;113(2-3):189-99.

29. Shamsi S, Lau A, Lencz T, Burdick KE, Derosse P, Brenner R, et al. Cognitive and symptomatic predictors of functional disability in schizophrenia. Schizophr Res. 2011;126(1-3):257-64.

30. Milev P, Ho BC, Arndt S, Andreasen NC. Predictive values of neurocognition and negative symptoms on functional outcome in schizophrenia: a longitudinal first-episode study with 7-year follow-up. Am J Psychiatry. 2005;162(3):495-506.

31. Tempier R, Balbuena L, Lepnurm M, Craig TK. Perceived emotional support in remission: results from an 18-month follow-up of patients with early episode psychosis. Soc Psychiatry Psychiatr Epidemiol. 2013;48(12):1897-904.

32. Buchanan J. Social support and schizophrenia: a review of the literature. Arch Psychiatr Nurs. 1995;9(2):68-76.

33. Lambo TA. Further neuropsychiatric observations in Nigeria, with comments on the need for epidemiological study in Africa. Br Med J. 1960;2(5214):1696-704.

34. Ohaeri JU. Perception of the social support role of the extended family network by some Nigerians with schizophrenia and affective disorders Soc Sci Med. 1998;47(10):1463-72.

35. Agid O, Kapu S, Arenovich T, Zipursky RB. Delayed-onset hypothesis of antipsychotic action: a hypothesis tested and rejected. Arch Gen Psychiatry. 2003;60(12):1228-35.

36. Chen Y, Chen K, Chiu C, Tai M, Lung F. Early predictors of poor treatment response in patients with schizophrenia treated with atypical antipsychotics. BMC Psychiatry. 2018;18(1):376.

37. Yildiz M, Yazici MK, Yagcioglu AEA, Karahan S, Sevik AE, Gurses N. Prediction of response to antipsychotic drugs in schizophrenia patients within the early phase of treatment. Bull Clin Psychopharmacol. 2015;25(4):390-8.

38. Stentebjerg-Olesen M, Ganocy SJ, Findling RL, Chang K, DelBello MP, Kane JM et al. Early response or nonresponse at week 2 and week 3 predict ultimate response or nonresponse in adolescents with schizophrenia treated with olanzapine: results from a 6-week randomized, placebo-controlled trial. Eur Child Adolesc Psychiatry. 2015;24(12):1485-96. 